\title{
Lessons learned from the first evaluation of the Medical Insurance for a New Generation: Bridging research and policy
}

\author{
Ricardo Pérez-Cuevas, MD, DrSc,(1) Salomón Chertorivski, MPP,(2) Gabriel Cortés-Gallo, MD, (3) \\ Evelyne Rodríguez-Ortega, MPP,(4) Francisco Caballero, MSc, ${ }^{(5)}$ Onofre Muñoz-Hernández, MD, MSc. ${ }^{(6)}$
}

\begin{abstract}
Pérez-Cuevas R, Chertorivski S, Cortés-Gallo G, Rodríguez-Ortega E, Caballero F, Muñoz-Hernández O. Lessons learned from the first evaluation of the Medical Insurance for a New Generation: Bridging research and policy. Salud Publica Mex 2012;54 suppl I:S90-S97.
\end{abstract}

\begin{abstract}
The first evaluation of the Medical Insurance for a New Generation program (SMNG) was conducted in 2009. A mixed-method approach was used to obtain a comprehensive picture of SMNG members and the program itself. The evaluation comprised: I) Program design; 2) Social and health conditions of its members; 3); Evaluation of SMNG's performance by measuring coverage, productivity and efficiency; 4) Families health expenditures. The lessons learned for the program are that SMNG is focused on a vulnerable segment of the population with pervasive unmet health needs; prevalence of malnutrition, anemia and other conditions remains high. Further efforts are necessary to deploy the program where it is most needed, particularly in rural areas; most of its members are urban dwellers. However, more needs to be done to educate members about the importance of preventive care and to build the capability of health providers to provide high quality care. Families are still experiencing hardship to provide medical care to their children, so additional efforts are needed to decrease out-of-pocket and catastrophic expenditures. The lessons learned for the evaluation allow concluding that this first evaluation set the groundwork for better-targeted subsequent interventions and evaluations aimed at showing the impact of SMNG to bridge existing gaps in equity, access, coverage, and health status of Mexican children.
\end{abstract}

Key words: infants' health; preschool children's health; health program; social protection for health; program evaluation; exico
Pérez-Cuevas R, Chertorivski S, Cortés-Gallo G, Rodríguez-Ortega E, Caballero F, Muñoz-Hernández O. Lecciones aprendidas de la primera evaluación del Seguro Médico para una Nueva Generación.

Salud Publica Mex 2012;54 supl I:S90-S97.

\section{Resumen}

La primera evaluación del Seguro Médico para una Nueva Generación (SMNG) se llevó a cabo en 2009. La evaluación utilizó métodos mixtos para obtener una imagen completa de los miembros del SMNG y del programa. La evaluación comprendió: I) el diseño del programa, 2) las condiciones sociales y de salud de los miembros, 3 ) acceso y uso de los servicios de salud, 4) la calidad de los servicios de atención ambulatoria y hospitalaria y 5) el efecto en los gastos de salud de las familias. El SMNG está enfocado a la población vulnerable con necesidades de salud no satisfechas, donde persiste la prevalencia de la desnutrición, anemia y otras enfermedades. Son necesarios esfuerzos adicionales para aumentar la cobertura del programa en zonas rurales donde la necesidad es mayor; pues la mayoría de sus miembros habitan en áreas urbanas, también es indispensable fortalecer la atención preventiva y fortalecer la capacidad de los proveedores de salud para proporcionar atención de alta calidad. Las familias todavía están experimentando dificultades para prestar atención a sus hijos, son necesarios esfuerzos adicionales para disminuir los gastos de bolsillo y catastrófico. Esta primera evaluación establece las bases para intervenciones y evaluaciones posteriores sustentadas en objetivos mejor definidos y enfocados a demostrar que SMNG está disminuyendo las brechas existentes en equidad, acceso, cobertura y estado de salud de la niñez mexicana.

Palabras clave: salud infantil; salud preescolar; programas de salud; protección social en salud; evaluación de programas; Mexico

(I) Centro de Estudios Económicos y Sociales en Salud. Hospital Infantil de México Federico Gómez. México.

(2) Comisión Nacional de Protección Social en Salud, Secretaría de Salud. México.

(3) Dirección Adjunta, Seguro Médico para una Nueva Generación, Secretaría de Salud. México.

(4) Departamento de Evaluación de Políticas, Hospital Infantil de México Federico Gómez. México.

(5) Coordinación de Asesores, Comisión Nacional de Protección Social en Salud, Secretaría de Salud. México.

(6) Dirección de Investigación, Hospital Infantil de México Federico Gómez. México

Received on: February II, 20II • Accepted on: October 25, 201 I

Corresponding author: Dr. Ricardo Pérez-Cuevas. Centro de Estudios Económicos y Sociales en Salud, Hospital Infantil de México Federico Gómez. Dr. Márquez 162, Col. Doctores. 06720 México DF, México. E-mail: ricardo_perezcuevas@prodigy.net.mx 
$\mathrm{I}^{\mathrm{n} m}$ 2007, Seguro Popular launched the new Medical Insurance for a New Generation (Seguro Médico para una Nueva Generación, SMNG) program with the aims of increasing access and coverage of healthcare for children $<5$ years old. SMNG is the largest public investment in the health of children under the age of 5 in Mexico.

The first step of SMNG was to affiliate children born since December $1^{\text {st }}, 2006$. The program follows the Seguro Popular basic principle of providing health insurance to people without social security benefits. Through this program children have access to preventive, curative and rehabilitation services.

SMNG is a tax-based medical insurance program that is part of the System for Social Protection for Health (Seguro Popular). SMNG finances medical services through allocating the funds to the decentralized Ministries of Health in the states and to the Under Secretary of Prevention and Promotion of Health for public health specific interventions.

The funds of SMNG coexist with other funds of Seguro Popular in such way that medical services for children are supported by three sources that are directed for specific medical conditions: a) SMNG funds to provide health care to 128 medical conditions, mostly neonatal illnesses and pre-defined public health interventions: Pneumococcal and rotavirus vaccines, infant hearing screening, cochlear implants, cold chain, metabolic screening; b) Fund for Protection against Catastrophic Expenditures (FPGC) that finances high-cost, lowprevalence diseases, such as cancer and care at neonatal intensive care units (NICU); and c) Universal Catalog of Health Services that comprises the most common ambulatory and hospital care medical conditions. ${ }^{1}$ The funds do not overlap with each other.

SMNG allocates the funds on a capitated basis to the decentralized Ministry of Health states. These funds are expected to increase and strengthen the supply of healthcare. SMNG coexists with several other health and social programs that are also focused on or have children within their target population, such as the National Program of Vaccination, the program Oportunidades and other programs. This variety of programs provides a safety healthcare net for children. The components of such programs can boost or complement each other with SMNG. For example, SMNG finances rotavirus and pneumococcal vaccines, it also provides the funds to strengthen the cold chain; therefore, it reinforces the actions of the National Program of Vaccination. Oportunidades program is a cash transfer program that, among other actions, encourages among its affiliates the use of health care services and attendance to health education programs; thus, from a social perspective, it contributes to improve the health of children. ${ }^{2}$ Though these programs do not duplicate the actions for children, ascertaining the effect attributable of each on the health status of their affiliates would be a relevant research question.

Similar large-scale programs aimed at providing health insurance to vulnerable children have been implemented in other countries. ${ }^{3}$ In 1992, the government of New York City initiated the Child Health Plus (CHPlus) program. Upon positive evaluation results on access, utilization, and quality of care, the program was expanded to the State of New York. ${ }^{4,5}$ The program was converted into the State Child Health Insurance Program (SCHIP) that targeted 11 million uninsured children. ${ }^{6,7}$

Following the mandate of evaluating government social policies, in 2009 Seguro Popular commissioned Hospital Infantil de México Federico Gómez (HIMFG) to conduct the first SMNG evaluation, which addressed four domains to obtain a comprehensive picture of SMNG affiliates and the overall program: 1) Program design; 2) Social and health conditions of its members; 3) Evaluation of SMNG's performance by measuring coverage, productivity and efficiency; 4) Families health expenditures (Table I).

\section{TABLE I}

Components of the 2009 Medical Insurance for a New Generation

\begin{tabular}{|c|c|c|}
\hline Components & Domain & Outcome variables \\
\hline Program & Design of SMNG & $\begin{array}{l}\text { Congruence with public } \\
\text { policies }\end{array}$ \\
\hline \multirow{6}{*}{$\begin{array}{l}\text { Affiliated } \\
\text { Population }\end{array}$} & Sociodemographic & $\begin{array}{l}\text { Social and demographic } \\
\text { conditions }\end{array}$ \\
\hline & Health status & $\begin{array}{l}\text { Nutritional status: } \\
\text { malnutrition, overweight, } \\
\text { obesity, anemia, mortality }\end{array}$ \\
\hline & Health care utilization & $\begin{array}{l}\text { Ambulatory care: } \\
\text { preventive and curative care }\end{array}$ \\
\hline & & Hospital care: curative care \\
\hline & $\begin{array}{l}\text { Families health } \\
\text { expenditures }\end{array}$ & $\begin{array}{l}\text { Expenditures for ambulatory } \\
\text { and hospital care }\end{array}$ \\
\hline & & Catastrophic expenditures \\
\hline \multirow[t]{2}{*}{ Health Services } & $\begin{array}{l}\text { Performance } \\
\text { measurement }\end{array}$ & $\begin{array}{l}\text { Indicators of productivity, } \\
\text { efficiency and effectiveness }\end{array}$ \\
\hline & & $\begin{array}{l}\text { Evaluation of tracers: low } \\
\text { birth weight, screening for } \\
\text { congenital hypothyroidism, } \\
\text { iron supplementation, } \\
\text { monitoring of growth and } \\
\text { development of children, } \\
\text { and neonatal respiratory } \\
\text { distress syndrome }\end{array}$ \\
\hline
\end{tabular}


The decision to evaluate these five domains is supported conceptually by the recommendation that any social intervention program should be assessed in five program domains: "1) the need for the program; 2) the design of the program; 3 ) the program implementation and service delivery; 4) the program impact or outcomes; and 5) the program efficiency." 8

A multi-method approach was used for the evaluation. ${ }^{9}$ It included a household survey with national and urban-rural representativeness. HIMFG partnered with Instituto Nacional de Estadística y Geografía to run the household survey. The evaluation included review of SMNG and FPGC registries, interviews with decision-makers and clinicians; revision of clinical charts, and analysis of available infrastructure in a representative sample of primary, secondary and tertiary-care medical facilities.

The evaluation took place two years after the introduction of the SMNG program. Practical reasons can support the pertinence of evaluating the program after two years. The program began to affiliate only children born after December 2006, thus the enrollment began gradually in the country. By the time of the evaluation, children would be between 6 months and 2.5 years old. Thus the characteristics of the cohort allowed to include relevant variables of interest for children's health such as conditions at birth, need for medical care at birth, i.e., admittance to neonatal intensive care units, feeding practices, attendance to preventive services, such as vaccines, and use of curative care for common conditions. In other words, the evaluation allowed ascertain whether SMNG children were exposed to a number of health interventions throughout time.

This paper has three sections, first the main results of the SMNG evaluation are discussed; next we address the flaws and strengths of the evaluation, then, in the conclusions and recommendations, we analyzed the role of SMNG within the Mexican health policies aimed at improving the health status of children.

\section{Main results of the 2009 SMNG evaluation}

\section{Evaluation of SMNG program design}

The evaluation of SMNG program design was conducted by estimating the potential capability of the program to contribute to the success of current public policies to facilitate access and coverage of health care to under-fives. The federal government had previously analyzed children's main health problems (morbidity and mortality), which justified designing and launching the SMNG.

The SMNG program spurs the decentralized $\mathrm{MoH}$ states to improve supply of healthcare services to children through promoting access to, delivery of, and allocating financial resources. SMNG is a component of the System for Social Protection of Health (Seguro Popular); therefore, it has finance, legal and organizational mechanisms available. The program also has design indicators such as progress of coverage (number of newborns affiliated with SMNG over the total number of newborns without social security) throughout the years, amount of budget spent in relation to the allocated budget, percentage of children cared for by using FPGC funds, and percentage of FPGC funded children that are being followed up, among others.

The analysis of the program's design allowed the assumption that SMNG might have the capability to accomplish its objectives of contributing to reduce morbidity and mortality of neonates, infants and preschool children. Nonetheless, SMNG design has strengths and weaknesses. By definition, all under-fives without social security should become members of this program, however, the program only affiliates children born since December 2006. Therefore, when the evaluation was conducted, the cohort had children from 6 months up to 2.5 years of age, and older children had not been enrolled in the program. Though the decision to include only newborns may have a positive impact given that $40 \%$ of deaths among under-fives happen in newborns (0-28 days of age), ${ }_{1}^{10}$ it is possible to assume that allowing the enrollment of children up to 5 years could accelerate the decrease of morbidity and mortality rates among preschoolers. Mexican children aged 2-5 years still have high prevalence rates of malnutrition, anemia and infectious diseases. ${ }^{11-13}$

The evaluation of the design also revealed that the SMNG information system needs further development. The system showed inconsistencies such as delays in the registries of progression of enrollment in each state, and lack of expedited supervision mechanisms to oversee the availability of the infrastructure or to measure quality of care, among others. These weaknesses do not allow the full use of indicators in the SMNG operating rules and restrict the possibility of SMNG to fulfill its role as steward of the health status of its members. Further studies analyzing in-depth the problems in the affiliation system would help to focus better the strategies to improve it, particularly in rural areas where access to health services is more restricted.

\section{Social and health conditions of SMNG members}

\section{Socio-demographic conditions}

The socio-demographic conditions of the SMNG children's families confirm that SMNG has indeed focused on the vulnerable segment of the population with per- 
vasive health needs reflected in the children's health status. The analysis showed that $72 \%$ of SMNG members were predominantly urban dwellers with only $28 \%$ living in rural areas. The socioeconomic characteristics between rural and urban populations were different with the most vulnerable population living in rural areas. Low literacy, higher average number of children per mother (rural 2.68; urban 2.18), overcrowding and poor household infrastructure were observed mostly in rural households. Mothers were not fully aware of the membership of their children in SMNG. They knew that their child was a member to either SMNG or Seguro Popular or both, but $8 \%$ did not know that the child was enrolled at all. This confusion about whether or not the cost of their child's medical care is covered and about which services the child is entitle to receive affects the mother's willingness to seek medical care, because it causes uncertainty about the cost and doubts in terms of the capability of the family to afford health care. The up-to-date information regarding the social conditions of SMNG members is an important finding not only for SMNG, but also for other programs that include children as part of their target population.

SMNG affiliation overlapped with social security affiliation in $9.7 \%$ of cases. This overlapping is explainable because SMNG is a voluntary program and it is very possible that at the time of the interview, one or both parents were in a job that provided social security benefits. This finding indicates the need to establish communication channels between healthcare systems, because of the implications on access to healthcare and on healthcare costs. The access implication means the possibility of presenting to either $\mathrm{MoH}$ or social security facilities and it is essential that there is continuity and coordination of information between institutions for program members. This service overlap also increases per-capita expenditures. SMNG is a tax-based program and its enrollment is on a voluntary basis; whereas affiliation with Social Security is compulsory for formal sector employees. The social security revenues come from the government (tax-based), the employee and the employer. The fact that $9.7 \%$ of SMNG members were affiliated with both SMNG and social security means that their healthcare is being funded from different sources thus increasing healthcare costs.

\section{Feeding practices and health status}

The household survey included the ascertainment of feeding practices and some characteristics of children's health status. The evaluation reported flawed breastfeeding practices; $8 \%$ of children were not breastfed and the duration of breastfeeding in children living in rural and urban areas was different: $80.0 \%$ versus $56 \%$ at six months, and $73.0 \%$ versus $48.4 \%$ at one year of age, respectively. Ideally, all children should be breastfed during the first year of life. We also observed that the introduction of complementary nutrition did not begin after six months of age; but in many cases, before this age. Furthermore, the food children received at the first and second year of age was not fully nutritionally appropriate.

The nutritional status of children showed marked differences; $75 \%$ of children had adequate nutritional status (based on the measurements of age, height and weight). However, rural children had poorer nutritional status than urban children. Also, the problems of malnutrition increase with age. At one year of age, the overall prevalence of stunting (retarded growth for age) was $13.6 \%$ (rural: $17.2 \%$; urban: $12.1 \%$ ) and at two years of age it increased to above $20 \%$ and emaciation and overweight was observed in 3.9\% and 6.3\%, respectively. These findings are similar to results from other nation-wide surveys. ${ }^{14,15}$ From the nutritional status of iron measured in a subsample of children, we observed that $34.2 \%$ of children suffered from anemia and the prevalence was higher among rural children and among children in the second year of life. In this sample, a number of associated factors, such as poor maternal breastfeeding practices, early weaning and household income were found to be associated with this problem.

These findings reinforce the notion that it is imperative to continue to strengthen current programs and interventions aimed at educating mothers about the benefits of breastfeeding up to one year of age and of adequate alimentary practices during the first two years of life. Also, screening practices for anemia in primary care clinics needs to be reinforced. Malnutrition, manifested in either low weight or obesity, is caused by a multiplicity of factors beyond the control of healthcare services, however, health policies are instrumental in tackling these problems, and such policies should be maintained and scrutinized continuously.

\section{Mortality}

Infant mortality is a well-known indicator of health systems performance. It points out the quality of care that under-fives receive. In Mexico, the neonatal mortality rate (NMR) has declined slowly — from 15.7 to 10.3 per 1000 live births over the 25 -year period 1980 to $2005 .{ }^{16}$ Most of deaths happen during the first year of life and particularly among newborns (birth to 28 days of age). ${ }^{17}$ The 2009-SMNG household survey included information regarding child deaths. The key findings are the high percentage of neonatal deaths $(67.9 \%)$. Of 
that percentage, $95.7 \%$ had received medical care during the hebdomadal period and 58\% at age of 7 to 28 days. Information regarding the cause of death was taken from the death certificate in $75.8 \%$ and from the parents in $24.2 \%$. During the neonatal period, the main causes of death were prematurity, low birth-weight, asphyxia, sepsis and congenital malformations. After the neonatal period, the main causes were infectious diseases, such as sepsis, pneumonia and acute diarrhea. ${ }^{*}$ The fact that most newborns received medical care before death should attract the attention of decision-makers and clinicians to explore in-depth the percentage of avoidable deaths. It is obvious that these children had access and used the services, however, it is unknown whether they received timely and high quality care.

\section{Access and use of health services}

Measuring access should always be under a specific conceptual framework that helps to delimitate the phenomenon under analysis. The point of departure should be the context established by current health policies and include the characteristics of the population and of the healthcare system. ${ }^{18} \mathrm{~A}$ useful approach is to consider potential access and effective access. Potential access is related to the characteristics of the provider and of the population that make possible for individuals to enter the healthcare system. Effective access refers to actual use of the services. ${ }^{19}$

The 2009 SMNG evaluation focused on use of services for preventive and curative care. Preventive services refer to well child visits, visual and hearing screening tests, iron and vitamin A supplementation and prescription of anti-parasitic drugs, attendance of the mother to educational activities, and vaccines that the child received - measles / mumps / rubella (MMR); pentavalent combination - diphtheria, tetanus, acellular pertussis, polio and Haemophilus influenzae type $b$ (DTaP-IPV/ Hib), pneumococcal, seasonal influenza and rotavirus vaccines. Curative care included ambulatory visits, emergency room and hospital admissions for acute diarrhea, acute respiratory infections and other causes. Low percentages of preventive care services were observed such as well-child visits (rural 37.5\%; urban 25.05). Furthermore, the rates of coverage for completed schemes of vaccines (according to age) were also below expected figures: measles/mumps/rubella:

\footnotetext{
* Flores S, Klünder M, Muñoz O, Martinez S. An approximation of the mortality rate in infants under 2 years old covered by the Medical Insurance for a New Generation.
}

urban $83.3 \%$, rural $85 \%$; pentavalent combination: urban $71 \%$, rural $74.7 \%$; rotavirus: urban $59.7 \%$, rural $60.4 \%$; seasonal influenza: urban $36.4 \%$, rural $37.3 \%$. The information was collected from the vaccination booklets and we did not collected information about vaccination from other sources.

Regarding curative services, most children $(81 \%)$ had been taken for medical care. The analysis considered mostly acute diarrhea, acute respiratory infections and other conditions. Most of services were provided at primary care settings and only $5 \%$ of children were admitted for hospital care.

From the population perspective, the factors associated with use of preventive or curative care were related to a better socioeconomic status, such as mothers' literacy or attendance to antenatal care. Children in vulnerable conditions such as those younger than 1 year of age, born prematurely or suffering from infectious diseases were taken more often to preventive care.

Still, there exists a wide margin to improve the uptake of preventive care. The mothers that received antenatal care, attended educational activities or were better educated took their children more often for preventive care and curative care. This finding points out the importance of health services to continue carrying out educational activities whilst providing actual services to the users.

As mentioned earlier, not all mothers were aware that their children were SMNG program members, and so were more likely to not seek preventive or curative care. From the supply side perspective, the users should be aware that they have a regular source of care, which services they are entitled to receive and to what extent these services will not constitute hardship for them. Currently, SMNG members are not familiar enough or at all with their entitlement to healthcare services. It is expected that people who know their rights will modify their patterns of healthcare utilization. The SCHIP program reported similar results regarding the population's lack of knowledge about membership in the program and the hassles to affiliate their children. ${ }^{6}$

\section{Quality of ambulatory and hospital healthcare services}

There are several definitions for quality of care. The Institute of Medicine definition is as follows: "Quality of care is the degree to which health services for individuals and populations increase the likelihood of desired health outcomes and are consistent with current professional knowledge." Further, a healthcare system should have six specific aims for improvement: safety, effectiveness, patient-centered, timely, efficient and equitable. ${ }^{20}$ 
One of the main goals of the SMNG program is that its members receive high quality medical care. The 2009-SMNG evaluations comprised different aspects related to healthcare performance within which quality of care was considered. Review of SMNG and FPGC registries served this purpose. SMNG has performance indicators within its operating rules. ${ }^{*}$ The evaluation of these indicators revealed good progress in the rates of recruitment, in accordance with SMNG programmatic goals and a high rate of utilization of primary care services, although low rates of hospital admissions and follow-up of cases were observed.

Quality of medical structure and critical processes at medical facilities were also evaluated. Health personnel and physical structure of the medication facilities in each level of care were evaluated through a set of eight surveys. In addition, clinical charts in primary and secondary levels of care were audited for four tracers: low birth weight, congenital hypothyroidism screening, iron supplementation, healthy child visits. At tertiary care hospitals, the audit focused on newborns with respiratory distress syndrome cared for at neonatal intensive care units. These five tracers are within the $\mathrm{MoH}$ priority programs. The SMNG enrollment process and the flow of financial resources were evaluated as well. The indices to evaluate the general structure and the clinical structure of the facilities showed that most primary care facilities were poorly equipped as were secondary care hospitals. Poorly equipped medical facilities have less capability to satisfy demand and provide good quality care. Regarding tertiary care hospitals, only those with neonatal intensive care units were analyzed. The general and clinical structure of these facilities was considered satisfactory. ${ }^{21}$

The evaluation of the tracers reported limitations in the quality of care, the lowest scores (poor quality) were observed in primary care settings, whereas secondary and tertiary care facilities scored better. Limitations in quality were observed in the different variables that served to evaluate the process of care in each tracer. The aspects comprised availability of information, clinical care, opportunity of diagnosis and treatment and so forth.

The combination of poor structural conditions and low quality of care, mainly in primary care facilities

\footnotetext{
* Jasso L, Durán L, Flores S. Niches of Opportunity in the Medical Insurance for the New Generation to improve its management, processes, morbidity and mortality of children protected by the program.
}

where most of services for SMNG members are delivered, and the limitations found in secondary and tertiary levels of care, represent that the expected improvements in health outcomes would not be fully attained. It is worth mentioning that the evaluation of quality of care was made through collecting data from primary sources (interviews and clinical charts) and these sources also had weaknesses. Thus, measuring quality of care regularly will be subject to a number of limitations in the quality and availability of information itself. These findings stress the need to consider the importance of having good and reliable sources of information that allow measuring quality of care regularly.

\section{Effect on health expenditures of the families}

The System of Social Protection for Health (Seguro Popular) aims at reaching fair health financing and decreasing catastrophic health expenditures. Different evaluations have shown that this program contributes to decreasing household health expenditures. A mathematic simulation model applied to Seguro Popular members reported that out-of-pocket expenditures would decrease by $40 \%(3.4 \%$ to $1.6 \%){ }^{22}$ The analysis of intention to treat estimates showed a $23 \%$ reduction of catastrophic expenditures and reduction on health spending in poor households. ${ }^{23}$ Previous evaluations focused on overall health expenditures for Seguro Popular members and no previous analysis exists focused on children.

The 2009-SMNG household survey gathered information about household income and health expenditures for children. The results showed that $63 \%$ of households spent money on children's health care. This happened more often in urban households. As mentioned earlier, SMNG members are mostly urban and it is possible that this circumstance influences the result. Regarding catastrophic expenditures, the range varied from $4.3 \%$ to $11.6 \%$ depending on the definition. Most expenditures were on medicines and payment of medical services. ${ }^{24}$ Most monetary resources to cover catastrophic expenditures came from a variety of sources such as money borrowed from friends and relatives, pawning of assets and savings. It is important to note that $15 \%$ of families postponed seeking healthcare and $10 \%$ decided not to seek care at all due to their incapability to cover the expenses. These percentages increased in those families that incurred in catastrophic expenditures $-26.5 \%$ postponed and $18.3 \%$ called off medical care. Further efforts are necessary to expand the benefits of SMNG program to rural areas and to decrease families' hardship due to health care expenditures. 


\section{Strengths and weaknesses}

This first evaluative study has several limitations and its results should be interpreted with care. The study did not have a comparison group, which would have strengthened the design. It has national and urban-rural representativeness and given the existing wide variability among the states in terms of their health conditions, infrastructure and socio-demographic conditions, obtaining state-representative samples would also be valuable. Further information about the affiliation and use of other health care services was missing. Almost $10 \%$ were affiliated with the social security, therefore, some results regarding use of preventive and curative services could be biased.

Regarding the five domains that the literature recommends to evaluate social programs: 1 ) the need for the program 2) program design; 3) program implementation and service delivery; 4 ) program impact and outcomes; and 5) program efficiency. ${ }^{8}$ The present evaluation did not included program impact and outcomes and program efficiency.

Among the strengths we can mention that most of the information for this evaluative study came from primary sources, such as a household-survey that was fully conducted by the National Institute of Geography and Statistics and through interviewing medical doctors, medical directors, SMNG decision-makers and reviewing clinical charts. The results can be interpreted as the baseline evaluation of the SMNG program and can be used as the departure point for subsequent evaluations and for defining specific interventions.

Evaluating large-scale programs is complex and not straightforward. This evaluation was focused on design, health status, coverage, quality of care and health expenditures. It took into consideration the presence of socioeconomic factors and contextual factors, such as routine care services for selected tracers, however, we did not fully consider the effect of other interventions or programs focused on children. SMNG is within a stream of social programs such as Oportunidades, Procampo and so forth, therefore, straightening out the fraction of the contribution of each of these programs to the health of children in the Mexican context has not been carried out. The limitations to obtain up-to-date information from other programs, methodological complexities and further investment in evaluative studies are necessary.

\section{Conclusions and recommendations}

Regarding the program evaluation, the main findings allow identifying that further efforts are necessary to deploy the program where it is most needed, particularly in rural areas; most of its members are urban dwellers. Additionally, more needs to be done to educate members about the importance of preventive care and to build the capability of health providers to provide high quality care. Families are still experiencing hardship to provide medical care to their children, so additional efforts are needed to decrease out-of-pocket and catastrophic expenditures. Regarding the evaluation of health care services, implementing measures of quality of care are necessary. SMNG provides the financial resources to the decentralized $\mathrm{MoH}$ in the states and the program should promote not only a continuous increase in children's enrollment, but also that its members gain access to healthcare that is continuous, of high quality and with timely and appropriate referral. ${ }^{3}$

The program SMNG is targeting a vulnerable population, children under five years old. The findings support the conclusion that a program like this is necessary to improve the health conditions of Mexican children. As explained earlier, SMNG supports public health interventions, such as rotavirus and pneumococcal vaccines, and the cold-chain. Also, it allocates capitated funds to the states to strengthen the health care system and it pays directly for the treatment of 128 health conditions. Investment in the health of children has short and long term gains. In the short term assures healthy children that can reach their potential growth and development; in the long term it also contributes to healthier adults. The health needs of Mexican children justify the allocation of resources that are targeted to them; this can maximize the returns of the investment in terms of better health status. The results of the evaluation provide to the stakeholders evidence-based information to make decisions about the pertinence of this program.

As for the evaluation method, we can conclude that this study aims to build on the growing body of evaluations aimed at measuring the effect of providing social protection for health to people without social security. The program covers a broad spectrum of interventions aimed at improving children's health. The direct benefits of SMNG are expected to accrue and this first comprehensive evaluation sets the groundwork to continue carrying out crosscutting evaluations that would comprise aspects related to the rates of enrollment, health status, use of preventive and curative care, and impact on families' expenditures on health. However, the judgment on SMNG should not be only focused on the number of enrolled children; subsequent evaluations should show the increase of services utilization by SMNG members and that health gains exist. The improvement of the health status of SMNG children, particularly among those living in rural areas, would be the best proxy of the success of the program. Also, further evaluations 
should provide evidence of the program's positive effect on decreasing families' health expenditures. The Seguro Popular/SMNG information system should be strengthened to facilitate up-to-date and high quality data. An additional issue to be considered is the measurement of the effect attributable to other programs in the health of children. Given the number of programs that have a direct or indirect effect on the health of children, future evaluations should explore in-depth this aspect.

Relevant evaluation questions remain unanswered. For example, evaluating how the decentralized $\mathrm{MoH}$ in each state manages resources and whether the expected results are being obtained is relevant. This type of evaluation would present the possibility of learning whether SMNG actually bridges the gaps in equity, access, coverage and health status of Mexican children.

Declaration of conflict of interests: The authors declare that they have no conflict of interests.

\section{References}

I. Diario Oficial. Acuerdo por el que se emiten las Reglas de Operación del Programa Seguro Médico para una Nueva Generación para el ejercicio fiscal 20I I. Mexico. Diario Oficial. Miercoles 29 de diciembre de 2010. 2. Fernald LCH, Gertler P, Neufeld LM. The Importance of Cash in Conditional Cash Transfer Programs for Child Health, Growth and Development: An Analysis of Mexico's Oportunidades. Lancet 2008; 37I: 828-837. 3. Starfield B. Evaluating the State Children's Health Insurance Program: Critical Considerations. Annual Review of Public Health 2000; 2I: 569-585. 4. Szilagyi PG, Zwanziger J, Rodewald LE, Holl JL, Mukamel DB, Trafton $S$, et al. Evaluation of a state health insurance program for low-income children: implications for state child health insurance programs. Pediatrics 2000; 105(2):363-37I.

5. Szilagyi P, Dick A, Klein J, Shone L, Zwanziger J, Mclnerny T. Improved Access and Quality of Care After Enrollment in the New York State Children's Health Insurance Program (SCHIP). Pediatrics 2004; I 13;e395e404 DOI: 10.1542/peds.I I3.5.e395

6. Dubay L, Hill I, Kenney G. Lisa Dubay, Five Things Everyone Should Know about SCHIP. New Federalism, Issues and Opportunities. The Urban Institute. Series A, No. A-55, October 2002.

7. Rosenbach M, Irvin C, Merrill A, Shulman S, Czajka J, Trenholm Ch et al. National Evaluation of the State Children's Health Insurance Program: A Decade of Expanding overage and Improving Access. Mathematical Policy Research, Inc. September 2007.
8. Rossi P, Freeman H, Lipsey M. Evaluation a systematic approach 6th ed. Thousand Oaks, California: Sage Publications, 1999.

9. Pérez-Cuevas R, Muñoz O, Rodríguez E, Jasso L, Flores S, Durán L, et al. Design of the 2009 evaluation of the Medical Insurance for a New Generation Program. Salud Publica Mex 2012;SII-SI9

10. World Health Organization. Neonatal and perinatal mortality : country, regional and global estimates. Geneva: WHO Press, 2006

II. Ávila F, Shamah T. Diagnóstico de la magnitud de la desnutrición infantil en México. Zuñiga E. México ante los desafíos del milenio. México; CONAPO, 2005.

12. Rivera J, Shamah T, González T, Hernández B, Sepúlveda J. Encuesta Nacional de Nutrición 1999. Estado nutricio de niños y mujeres en México. Cuernavaca: Instituto Nacional de Salud Pública, 2001.

13. Richardson V, Hernández J, Quintanar M, Esparza M, Johnson B, Gómez $\mathrm{C}$, et al. Effect of rotavirus vaccination on death from childhood diarrhea in Mexico. N Eng J Med 2010;362:299-305.

14. Olaiz-Fernandez G, Rivera-Dommarco J, Shamah-Levy T, Rojas R, Villalpando-Hernandez S, Hernandez-Avila M, et al. Encuesta Nacional de Salud y Nutrición, 2006. Cuernavaca, Morelos, Mexico: Instituto Nacional de Salud Pública, 2006.

15. Rivera Dommarco J, Shamah-Levy T, Villalpando Hernandez S, Gonzalez de Cossio T, Hernandez Prado B, Sepulveda J. Encuesta Nacional de Nutrición, 1999. Cuernavaca, Morelos, Mexico: Instituto Nacional de Salud Pública, 200I.

16. Perdigón-Villaseñor G, Fernández-Cantón SB. La mortalidad neonatal y postneonatal en México, 1980-2005. Bol Med Hosp Infant Mex 2008;

65: $4|2-4| 4$

17. Black RE, Cousens S, Johnson HL, et al. Global, regional, and national causes of child mortality in 2008: a systematic analysis. The Lancet 2010;375:1969-1987.

18. Aday L.A and Andersen R. A framework for the study of access to medical care. Health Services research 1974; 9: 208-220.

19. Andersen R, McCutcheon A, Aday LA, Chiu GY and Bell R. Exploring dimensions of access to medical care. Health Services Research, 1983; 18 (I): 49-74.

20. Institute of Medicine. Crossing the quality chasm. A new health system for the $2 I^{\text {st }}$ century. Washington DC: National Academy Press, $200 \mathrm{I}$. 2I. Duran-Arenas L, Aldaz V, Jasso L, Flores S, Hernandez L, Zurita J. Quality of Health Care of the Medical Units that provide services for Medical Insurance for a New Generation (SMNG) enrollees. Salud Publica Mex 2012;54 supl I:S42-S49.

22. Knaul F, Arreola-Ornelas H, Méndez O, Martínez A. Fair health financing and catastrophic health expenditures: potential impact of the coverage extension of the popular health insurance in Mexico. Salud Publica Mex 2005;47 Suppl I:S54-S65.

23. King G, Gakidou E, Imai K, Lakin J, Moore R, Nall C, et al. Public policy for the poor? A randomised assessment of the Mexican universal health insurance programme. Lancet 2009; 373: I447-I 454.

24. Rodríguez-Ortega EE, Pasillas-Torres EM. Family healthcare expenditure on children affiliated to the Medical Insurance Program for a New Generation. Salud Publica Mex. 2012;54 supl I: S65-S72. 